www.nature.com/pj

\title{
High refractive index of transparent acrylate polymers functionalized with alkyl sulfur groups
}

\author{
Muchchintala Maheswara ${ }^{1}$, Sang-Hyun $\mathrm{Oh}^{1}$, Jung-Jin $\mathrm{Ju}^{2}$, Seung Koo Park ${ }^{2}$, Suntak Park ${ }^{2}$ and Jung Yun Do ${ }^{1}$ \\ Several sulfur-containing acrylate polymers were developed for a high refractive index with high transparency and good \\ processing performance for thin films. A series of poly(methacrylate)s were synthesized by radical polymerization, in which thin \\ films are coated on a quartz substrate for optical characterization. One, two and three sulfur atoms were bound into acrylate \\ monomers and thermally copolymerized with methyl methacrylate. An alicyclic structure was used to achieve a dense molecular \\ volume of the sulfur-containing monomer. Refractive index was measured under visible light. The index linearly increased with \\ the sulfur-containing monomer content of the copolymer. Each homopolymer was predicted by an extrapolation method, resulting \\ in a high refractive index of $1.624-1.725$ at $589 \mathrm{~nm}$. An Abbe's number of $\sim 30$ was recorded for most sulfur polymers, \\ indicating low wavelength dispersion of the index. A polymer with dipolar functionality displayed an Abbe's number of 40.9 . \\ High optical transparency of films was observed at the wavelengths of the index measurement. All polymers were thermally \\ stable up to $\sim 250^{\circ} \mathrm{C}$ and exhibited glass transition around $100^{\circ} \mathrm{C}$. \\ Polymer Journal (2010) 42, 249-255; doi:10.1038/pj.2009.328; published online 23 December 2009
}

Keywords: high refractive index; optical materials; sulfur acrylate; transparent film

\section{INTRODUCTION}

Polymers and copolymers produced from sulfur-containing acrylates and methacrylates have a wide variety of applications in plastic lenses, optical disc substrates, optical fibers, paints, adhesives and sealants. ${ }^{1-4}$ Recently, high refractive index polymers and copolymers were reported for optical and microelectronic applications. ${ }^{5,6}$ The refractive index is an important materials property for manipulating light and has been elaborately controlled for optical waveguides, lenses and prisms. ${ }^{7}$ The use of organic polymers in optical waveguide devices, particularly for applications in optical networks based on wavelength division multiplexing, has been actively pursued in the last decade because of their ease of processing, low cost and good compatibility for integration with semiconductor components. ${ }^{8-11}$ Optical thin films contribute to reducing the volume occupied by lenses in optical assemblies, which can advantageously make an optical apparatus lightweight and small. ${ }^{12}$ A high refractive index was accomplished with organic polymers that are advantageous for easy and not expensive mass production. The index has been analyzed under the consideration of labile electrons and the density related to the structural compactness of organic materials. The introduction of polarizing groups as functional substituents considerably affects the refractive index of organic materials. ${ }^{5}$ In this study, we design soluble linear polyacrylates composed of particular acrylate monomers having a high refractive index. Many copolymers are prepared with various monomer contents. The refractive index of feasible homopolymers can be determined through a linear plot of the refractive index of the copolymer versus the monomer content. Recently, a dipolar structure was found to increase the refractive index of aromatic systems. ${ }^{5}$ A study indicated that polyacrylates were highly transparent toward visible light even though absorption tails from the electronic transition that occurred at around $400 \mathrm{~nm} .{ }^{5}$ A waveguide requires elaborate control of the refractive index of materials for long light transmission, and is composed of core and clad layers with different refractive indices. ${ }^{13,14}$ Polymeric optical lenses are divided into two types of polymers: one is thermoplastics, such as poly(methyl methacrylate), polycarbonate and cycloolefin polymers for industrial uses, ${ }^{15}$ and the second is thermosets, such as polythiols, ${ }^{16}$ polyisocyanates ${ }^{17}$ and resins from episulfides. ${ }^{18}$ The former is used in camera, pickup and projector lenses in which injection molding is applied. On the other hand, eyeglasses are manufactured by cast molding of thermoset polymers. Among the various physical properties required for such applications, the refractive index $(n)$ is essential. Highly refractive synthetic resin can yield thinner lenses with the same focal distance as that of low-refractive materials. In addition, Abbe's number $\left(V_{\mathrm{D}}\right)$, which is a key measure for refractive index dispersion, is also an important parameter for optical materials used in the visible region. ${ }^{19}$

Abbe's number is described by the equation $V_{\mathrm{D}}=\left(n_{\mathrm{D}}-1\right) /\left(n_{\mathrm{F}}-n_{\mathrm{C}}\right)$, where $n_{\mathrm{D}}, n_{\mathrm{F}}$ and $n_{\mathrm{C}}$ are the refractive indices of materials at the wavelength of the sodium D $(589.3 \mathrm{~nm})$, hydrogen $\mathrm{F}(486.1 \mathrm{~nm})$, and hydrogen C $(656.3 \mathrm{~nm})$ lines, respectively. A large Abbe's number

${ }^{1}$ Department of Advanced Materials for Information and Display, Pusan National University, Busan, Republic of Korea and ${ }^{2}$ ETRI, 161 Gajeong-Dong, Yuseong-Gu, Deajeon, Republic of Korea

Correspondence: Dr JY Do, Department of Advanced Materials for Information and Display, Pusan National University, 30 Jangjeob-dong, Geumjeong-gu, Busan 609-735, Republic of Korea.

E-mail: jydo@ pusan.ac.kr

Received 8 September 2009; revised 13 October 2009; accepted 3 November 2009; published online 23 December 2009 
corresponds to low dispersion in the refractive index. ${ }^{20}$ Highly refractive materials generally exhibit a small Abbe's number. ${ }^{8-11}$ Sulfur-containing polymers are presumed to have a high refractive index from the Lorentz-Lorentz equation, ${ }^{8-12}$ because of high atomic refraction of the sulfur atom. Okubo et al. reported on such optical polymers prepared from the polymerization of 2,5-bis(2-thia-3-butenyl)-1,4-dithiane, the polyaddition of oligo[2,5-bis(thiomethyl)-1,4dithiane] and di- or triisocyanates, ${ }^{15}$ and episulfide-type copolymers exhibiting high refractive indices and high Abbe's numbers. ${ }^{16}$ Polymethacrylates, which are typical thermoplastics, are easy to polymerize and yield transparent films suitable for optical materials. However, a material having a high refractive index usually has a small Abbe's number, ${ }^{21}$ whereas sulfur-containing methacrylates have high refractive indices and large Abbe's numbers. ${ }^{22,23}$ Several nonorganic groups, including sulfur, germanium, phosphorus, titanium and halogens have been known to induce higher refractive indices. ${ }^{15}$ Thus, it is worthwhile to develop new optical acrylate polymers including heteroatom substituents for high refractivity. To reduce refractive index dispersion, we focused on an alicyclic group, which also attains a refractive index higher than that of an acyclic moiety. ${ }^{16,17}$ This research includes a novel design of transparent acrylic monomers for a high refractive index and development of a convenient synthesis pathway.

\section{EXPERIMENTAL PROCEDURE}

\section{Materials and characterization}

All reagents were purchased from Sigma-Aldrich International (St Louis, MO, USA) and the reagent-grade solvents were dried when necessary and purified by vacuum distillation. ${ }^{1} \mathrm{H}$-nuclear magnetic resonance (NMR) and ${ }^{13} \mathrm{C}-\mathrm{NMR}$ spectroscopy experiments (Bruker AM-300 spectrometer, Bruker BioSpin International, Faellanden, Switzerland) were used to characterize the molecular structure of the intermediate compounds and functional methacrylate monomers. Mass spectra were recorded on an Agilent 1200LC/1100 MSD SL mass spectrometer (Agilent Technologies, Marlborough, MA, USA). A MAGNA-IR 750 spectrometer (Thermo Nicolet, Madison, WI, USA) was used to record Fourier transform infrared (IR) spectra. Differential scanning calorimetry and thermogravimetric analysis were performed on a Mettler Toledo DSC 822e (Mettler-Toledo International, Greifensee, Switzland) and on a TAG/SDTA 851e (Mettler-Toledo International), respectively, at a heating rate of $10^{\circ} \mathrm{Cmin}^{-1}$ under a nitrogen atmosphere. A film sample was prepared on a special glass substrate (a rectangular prism with a refractive index of 1.788 at $589 \mathrm{~nm}$ ). Each copolymer solution ( $10 \mathrm{wt} \%$ in chloroform) was coated onto the glass substrate and kept in a convection oven at $110^{\circ} \mathrm{C}$ for $20 \mathrm{~min}$ to achieve a film thickness of $100-200 \mu \mathrm{m}$. Index measurement was determined at room temperature. The refractive indices of polymer films were measured at wavelengths of 486, 546, 589 and $656 \mathrm{~nm}$ by changing monochromatic filters with an Abbe's refractometer (Atago Co. Ltd, Tokyo, Japan, DR-M4). Each refractive index was averaged from three measurements. Abbe's number was calculated using Abbe's number equation $V_{\mathrm{D}}=\left(n_{\mathrm{D}}-1\right) /\left(n_{\mathrm{F}}-n_{\mathrm{C}}\right)$.

\section{Preparation of monomers}

Synthesis of 2-(N-methyl-N-(4-nitrophenyl)amino)ethanol (2). 1-Fluoro-4-nitrobenzene $1(2.8 \mathrm{~g}, 20.0 \mathrm{mmol})$ and 2-methylaminoethanol $(2.25 \mathrm{~g}, 30.0 \mathrm{mmol})$ were dissolved in dimethylsulfoxide $(60 \mathrm{ml})$, and potassium carbonate $(4.2 \mathrm{~g}$, $30 \mathrm{mmol}$ ) was added. The mixture was stirred at room temperature for $8 \mathrm{~h}$. After complete disappearance of the starting material, as indicated by thin layer chromatography (TLC), the resulting mixture was diluted with dichloromethane. The organic layer was washed with water $(30 \mathrm{ml})$ and brine $(20 \mathrm{ml})$ and dried over anhydrous $\mathrm{MgSO}_{4}$. The solvent was evaporated under reduced pressure. The residue was purified by column chromatography on silica gel using ethyl acetate and hexane $(1 / 4, \mathrm{v} / \mathrm{v})$ as the eluent to yield $2(3.3 \mathrm{~g}, 85 \%) .{ }^{1} \mathrm{H} \mathrm{NMR}(300 \mathrm{MHz}$, $\left.\mathrm{CDCl}_{3}\right) \delta: 1.70(\mathrm{~s}, 1 \mathrm{H}, \mathrm{OH}), 3.15\left(\mathrm{~s}, 3 \mathrm{H}, \mathrm{CH}_{3}\right), 3.64\left(\mathrm{t}, 2 \mathrm{H}, \mathrm{CH}_{2}\right), 3.91(\mathrm{t}, 2 \mathrm{H}$, $\left.\mathrm{CH}_{2}\right), 6.69(\mathrm{~d}, 2 \mathrm{H}, 2 \mathrm{CH}) 8.10(\mathrm{~d}, 2 \mathrm{H}, 2 \mathrm{CH})$.
Synthesis of 2-(N-methyl-N-(4-nitrophenyl)amino)-O-acrylate derivative (3). Compound $2(3.3 \mathrm{~g}, 17.0 \mathrm{mmol})$, methacrylic anhydride $(3.28 \mathrm{~g}$, $20.0 \mathrm{mmol}$ ), and a catalytic amount of 4-dimethylaminopyridine (DMAP) were dissolved in dichloromethane $(60 \mathrm{ml})$ containing triethylamine $\left(\mathrm{Et}_{3} \mathrm{~N}\right)$ $(3.55 \mathrm{ml}, 25.5 \mathrm{mmol})$. The mixture was stirred for $4 \mathrm{~h}$ at room temperature. The progress of the reaction was monitored by TLC and on completion the reaction mixture was diluted with water $(30 \mathrm{ml})$ and brine $(20 \mathrm{ml})$ and dried over anhydrous $\mathrm{MgSO}_{4}$. The solution was concentrated to produce a crude product and purified by column chromatography on silica gel using ethyl acetate and hexane $(1 / 7, \mathrm{v} / \mathrm{v})$ as the eluent to yield $3(3.2 \mathrm{~g}, 71 \%)$. m.p. $70-71^{\circ} \mathrm{C} \mathrm{IR}(\mathrm{KBr})$ : $v_{\max } 2935,2861,2653,1730,1636,1410,1363,1248,946,852 \mathrm{~cm}^{-1} ;{ }^{1} \mathrm{H}$ NMR $\left(300 \mathrm{MHz} \mathrm{CDCl}_{3}\right) \delta: 1.89\left(\mathrm{~s}, 3 \mathrm{H}, \mathrm{CH}_{3}\right), 3.13\left(\mathrm{~s}, 3 \mathrm{H}, \mathrm{CH}_{3}\right), 3.33\left(\mathrm{t}, 2 \mathrm{H}, \mathrm{CH}_{2}\right)$, $5.56(\mathrm{~s}, 1 \mathrm{H}, \mathrm{CH}), 6.67(\mathrm{~s}, 1 \mathrm{H}, \mathrm{CH}), 6.71(\mathrm{~d}, 2 \mathrm{H}, 2 \mathrm{CH}) 8.13(\mathrm{~d}, 2 \mathrm{H}, 2 \mathrm{CH}) .{ }^{13} \mathrm{C}$ NMR (75 MHz, $\mathrm{CDCl}_{3}$ ) 18.4, 24.4, 39.2, 51.1, 61.6, 110.7, 126.4, 126.5, 136.0, 153.6, 167.4. MS: Calcd for $\mathrm{C}_{13} \mathrm{H}_{16} \mathrm{~N}_{2} \mathrm{O}_{4}: 264.28$. Found: $264.11\left[\mathrm{M}^{+}\right]$.

Synthesis of (4-(methylthio)phenyl)methanol (5). Sodium borohydride (0.76 g, $20.0 \mathrm{mmol}$ ) was added to a stirred solution of 4-(methylthio)benzaldehyde 4 $(30 \mathrm{~g}, 20.0 \mathrm{mmol})$ in methanol $(60 \mathrm{ml})$. The mixture was stirred for $2 \mathrm{~h}$ at room temperature. After complete disappearance of the starting material, as indicated by TLC, the resulting mixture was diluted with ethyl acetate. The combined organic layer was washed with water $(30 \mathrm{ml})$, aqueous ammonium chloride $(20 \mathrm{ml})$, and brine $(20 \mathrm{ml})$ and dried over anhydrous $\mathrm{MgSO}_{4}$. The concentrated mixture was subjected to column chromatography on silica gel using ethyl acetate and hexane $(1 / 2, \mathrm{v} / \mathrm{v})$ as the eluent to yield $5(2.8 \mathrm{~g}, 90 \%) .{ }^{1} \mathrm{H} \mathrm{NMR}$ $\left(300 \mathrm{MHz}, \mathrm{CDCl}_{3}\right) \delta: 1.69(\mathrm{~s}, 1 \mathrm{H}, \mathrm{OH}), 2.49$ (s, 3H, $\left.\mathrm{CH}_{3}\right), 4.67$ (d, $2 \mathrm{H}, \mathrm{CH}_{2}$ ), 7.27-7.31 (m, 4H, 4CH).

Synthesis of 4-(methylthio)benzyl-O-methacrylate derivative (6). Compound 5 $(2.8 \mathrm{~g}, 18.0 \mathrm{mmol})$, methacrylic anhydride $(3.54 \mathrm{~g}, 21.6 \mathrm{mmol})$, and a catalytic amount of DMAP were dissolved in dichloromethane $(70 \mathrm{ml})$ containing triethylamine $\left(\mathrm{Et}_{3} \mathrm{~N}\right)(4.18 \mathrm{ml}, 30 \mathrm{mmol})$. The reaction mixture was stirred for $4 \mathrm{~h}$ at room temperature. The progress of the reaction was monitored by TLC and the resulting mixture was diluted with dichloromethane. The organic layer was washed with water $(30 \mathrm{ml})$ and brine $(20 \mathrm{ml})$ and dried over anhydrous $\mathrm{MgSO}_{4}$. The concentrated mixture was subjected to column chromatography on silica gel using ethyl acetate and hexane $(1 / 7, \mathrm{v} / \mathrm{v})$ as the eluent to yield 6 (liquid, $3.4 \mathrm{~g}, 84 \%$ ). IR (KBr): $v_{\max } 2969,1736,1673,1468$, 1380, 1260, 1089, 954, $854 \mathrm{~cm}^{-1}$; ${ }^{1} \mathrm{H}$ NMR (300 MHz, $\left.\mathrm{CDCl}_{3}\right) \delta: 1.94(\mathrm{~s}, 3 \mathrm{H})$, $2.44(\mathrm{~s}, 3 \mathrm{H}), 5.12(\mathrm{t}, 2 \mathrm{H}), 5.55(\mathrm{~s}, 1 \mathrm{H}), 6.13(\mathrm{~s}, 1 \mathrm{H}), 7.22(\mathrm{~d}, 2 \mathrm{H}) 7.29(\mathrm{~d}, 2 \mathrm{H})$. ${ }^{13} \mathrm{C} \mathrm{NMR}\left(75 \mathrm{MHz}, \mathrm{CDCl}_{3}\right.$ ) $\delta: 18.1,19.3,63.1,126.0,126.7,129.0,133.1,136.5$, 138.9, 163.8. MS: Calcd for $\mathrm{C}_{12} \mathrm{H}_{14} \mathrm{O}_{2} \mathrm{~S}: 222.30$. Found: $222.07\left[\mathrm{M}^{+}\right]$.

Synthesis of 2-(N-(4-(1,3-dithiolan-2-yl)phenyl)-N-methylamino)ethanol (8). Boron trifluride-diethyletherate $(1.49 \mathrm{~g}, 10.5 \mathrm{mmol})$ was added dropwise at $0{ }^{\circ} \mathrm{C}$ to a flask charged with a mixture of 4-(N-(2-hydroxyethyl)- $\mathrm{N}$-methylamino) benzaldehyde $7(1.79 \mathrm{~g}, 10.0 \mathrm{mmol})$ and 1,2-bis(trimethylsily)sulfanyl)ethane $(2.62 \mathrm{~g}, 11.0 \mathrm{mmol})$ in anhydrous dichloromethane $(30 \mathrm{ml})$. The mixture was stirred at room temperature for $10 \mathrm{~h}$ under nitrogen. After complete disappearance of the starting material, as indicated by TLC, the resulting mixture was diluted with dichloromethane. The organic layer was washed with water $(30 \mathrm{ml})$ and brine $(20 \mathrm{ml})$ and dried over anhydrous $\mathrm{MgSO}_{4}$. The concentrated mixture was subjected to column chromatography on silica gel using ethyl acetate and hexane $(1 / 4, \mathrm{v} / \mathrm{v})$ as the eluent to yield $8(2.0 \mathrm{~g}, 80 \%) .{ }^{1} \mathrm{H}$ NMR $\left(300 \mathrm{MHz}, \mathrm{CDCl}_{3}\right) \delta: 2.05(\mathrm{~s}, 1 \mathrm{H}, \mathrm{OH})$, $3.15\left(\mathrm{~s}, 3 \mathrm{H}, \mathrm{CH}_{3}\right), 3.32-3.34(\mathrm{~m}, 2 \mathrm{H}), 3.50-3.53(\mathrm{~m}, 2 \mathrm{H}), 3.64(\mathrm{t}, 2 \mathrm{H}), 3.91(\mathrm{t}, 2 \mathrm{H})$, $5.58(\mathrm{~s}, 1 \mathrm{H}), 6.66(\mathrm{~d}, 2 \mathrm{H}) 7.39(\mathrm{~d}, 2 \mathrm{H})$.

Synthesis of 2-(N-(4-(1,3-dithiolan-2-yl)phenyl)-N-methylamino)-O-methacrylate derivative (9). Compound $8(2.0 \mathrm{~g}, 8.0 \mathrm{mmol})$, methacrylic anhydride (1.42 g, $9.6 \mathrm{mmol})$, and a catalytic amount of DMAP were dissolved in dichloromethane $(30 \mathrm{ml})$ containing triethylamine $\left(\mathrm{Et}_{3} \mathrm{~N}\right)(2.1 \mathrm{ml}, 15 \mathrm{mmol})$. The reaction mixture was stirred at room temperature for $4 \mathrm{~h}$. The progress of the reaction was monitored by TLC and the resulting mixture was diluted with dichloromethane, washed with water $(30 \mathrm{ml})$ and brine $(20 \mathrm{ml})$, and dried over anhydrous $\mathrm{MgSO}_{4}$. The concentrated mixture was subjected to column chromatography on silica gel using ethyl acetate and hexane $(1 / 7, \mathrm{v} / \mathrm{v})$ as the eluent to yield $9(2.3 \mathrm{~g}, 85 \%)$. m.p. $61-62^{\circ} \mathrm{C} \mathrm{IR}(\mathrm{KBr}): v_{\max } 2975,1738,1682$, $1466,1385,1252,1075,850 \mathrm{~cm}^{-1} ;{ }^{1} \mathrm{H} \operatorname{NMR}\left(300 \mathrm{MHz}, \mathrm{CDCl}_{3}\right) \delta: 1.91(\mathrm{~s}, 3 \mathrm{H})$, 
$3.0(\mathrm{~s}, 3 \mathrm{H}), 3.31-3.34(\mathrm{~m}, 2 \mathrm{H}), 3.50-3.53(\mathrm{~m}, 2 \mathrm{H}), 3.65(\mathrm{t}, 2 \mathrm{H}), 4.31(\mathrm{t}, 2 \mathrm{H})$, $5.55(\mathrm{~s}, 1 \mathrm{H}), 5.64(\mathrm{~s}, 1 \mathrm{H}), 6.01(\mathrm{~s}, 1 \mathrm{H}), 6.67(\mathrm{~d}, 2 \mathrm{H}) 7.39(\mathrm{~d}, 2 \mathrm{H}) .{ }^{13} \mathrm{C} \mathrm{NMR}$ $\left(75 \mathrm{MHz} \mathrm{CDCl}_{3}\right) \delta: 18.6,39.0,40.4,51.3,56.7,62.1,112.2,126.1,127.1,129.2$, 136.2, 149.0. MS: Calcd for $\mathrm{C}_{16} \mathrm{H}_{21} \mathrm{NO}_{2} \mathrm{~S}_{2}$ : 323.46. Found: $323.10\left[\mathrm{M}^{+}\right]$.

Synthesis of 2-(2,2-dimethoxyethylthio)ethanol (11). 2-Mercaptoethanol (1.6 g, $20.0 \mathrm{mmol})$ and potassium carbonate $(2.76 \mathrm{~g}, 20.0 \mathrm{mmol})$ were successively added to a solution of bromoacetaldehyde-dimethylacetal $10 \quad(3.38 \mathrm{~g}$, $20.0 \mathrm{mmol})$ in dimethylformamide $(30 \mathrm{ml})$. The mixture was stirred at room temperature for $10 \mathrm{~h}$. After complete disappearance of the starting material, as indicated by TLC, the resulting mixture was diluted with dichloromethane. The organic layer was washed with water $(30 \mathrm{ml})$ and brine $(20 \mathrm{ml})$ and dried over anhydrous $\mathrm{MgSO}_{4}$. The concentrated mixture was subjected to column chromatography on silica gel using ethyl acetate and hexane $(1 / 4, \mathrm{v} / \mathrm{v})$ as the eluent to yield $11(2.8 \mathrm{~g}, 80 \%) .{ }^{1} \mathrm{H}$ NMR $\left(300 \mathrm{MHz}, \mathrm{CDCl}_{3}\right) \delta: 1.82(\mathrm{~s}, 1 \mathrm{H}$, $\mathrm{OH}) 2.61-2.74(\mathrm{~m}, 4 \mathrm{H}), 3.39\left(\mathrm{~s}, 6 \mathrm{H}, \mathrm{OCH}_{3}\right), 3.74(\mathrm{~d}, 2 \mathrm{H}), 4.42(\mathrm{t}, 1 \mathrm{H})$.

Synthesis of 3-(4-(1,3-dithiolan-2-yl)phenoxy)propan-1-ol (12). Boron trifluridediethyletherate $(2.79 \mathrm{~g}, 19.6 \mathrm{mmol})$ was added dropwise at $0^{\circ} \mathrm{C}$ to a solution of compound 11 (2.8 g, 17.0 mmol) and 1,2-bis(trimethylsily)sulfanyl)-ethane $(4.9 \mathrm{~g}, 20.3 \mathrm{mmol})$ in $30 \mathrm{ml}$ of anhydrous dichloromethane. The mixture was stirred at room temperature for $8 \mathrm{~h}$ under nitrogen. After complete disappearance of the starting material, as indicated by TLC, the resulting mixture was diluted with dichloromethane. The organic layer was washed with water $(30 \mathrm{ml})$ and brine $(20 \mathrm{ml})$ and dried over anhydrous $\mathrm{MgSO}_{4}$. The concentrated mixture was subjected to column chromatography on silica gel using ethyl acetate and hexane $(1 / 2, \mathrm{v} / \mathrm{v})$ as the eluent to yield $12(2.0 \mathrm{~g}, 60 \%) .{ }^{1} \mathrm{H} \mathrm{NMR}\left(300 \mathrm{MHz}, \mathrm{CDCl}_{3}\right) \delta$ : $1.84(\mathrm{~s}, 1 \mathrm{H}, \mathrm{OH}) 2.81\left(\mathrm{t}, 2 \mathrm{H}, \mathrm{CH}_{2}\right), 2.86\left(\mathrm{~d}, 2 \mathrm{H}, \mathrm{CH}_{2}\right), 3.15-3.19\left(\mathrm{~m}, 4 \mathrm{H}, \mathrm{CH}_{2}\right)$, $4.23\left(\mathrm{t}, 2 \mathrm{H}, \mathrm{CH}_{2}\right), 4.58(\mathrm{t}, 1 \mathrm{H}, \mathrm{CH})$.

Synthesis of 2-((1,3-dithiolan-2-yl)methylthio)ethyl methacrylate derivative (13). Compound $8(2.0 \mathrm{~g}, 10.0 \mathrm{mmol})$, methacrylic anhydride $(2.0 \mathrm{~g}$, $12.0 \mathrm{mmol}$ ), and a catalytic amount of DMAP were dissolved in dichloromethane $(30 \mathrm{ml})$ containing triethylamine $(2.0 \mathrm{ml}, 15 \mathrm{mmol})$. The reaction mixture was stirred at room temperature for $4 \mathrm{~h}$. The progress of the reaction was monitored by TLC and the resulting mixture was diluted with dichloromethane. The resulting mixture was washed with water $(30 \mathrm{ml})$ and brine $(20 \mathrm{ml})$ and dried over anhydrous $\mathrm{MgSO}_{4}$. The concentrated mixture was<smiles>C=C(C)C(=O)OCCN(C)c1ccc([N+](=O)[O-])cc1</smiles><smiles>C=C1C(=O)OCc2ccc(C)cc21</smiles><smiles>C=C(C)C(=O)OCCN(C)c1ccc(C2SCCS2)cc1</smiles>

7 8 9<smiles>COC(CBr)CSCCO</smiles><smiles>CCC(CO)SCC1SCCS1</smiles>

12<smiles>C=C(C)C(=O)OCCSCC1SCCS1</smiles>

13

Reagents and Conditions:

(i) 2-Methylaminoethanol, $\mathrm{K}_{2} \mathrm{CO}_{3}$, r.t., $8 \mathrm{~h}, 80 \%$.

(ii) Methacrylic anhydride, $\mathrm{Et}_{3} \mathrm{~N}$, DMAP, $\mathrm{CH}_{2} \mathrm{Cl}_{2}$, r.t., $4 \mathrm{~h}, 71 \%$.

(iii) $\mathrm{NaBH}_{4}, \mathrm{CH}_{3} \mathrm{OH}$, r.t., $2 \mathrm{~h}, 90 \%$.

(iv) 1,2-bis(trimethylsily)sulfanyl)ethane, $\left(\mathrm{C}_{2} \mathrm{H}_{5}\right)_{2} \mathrm{OBF}_{3}, \mathrm{CH}_{2} \mathrm{Cl}_{2}$, r.t., $10 \mathrm{~h}, 80 \%$.

(v) 2-Mercapto ethanol, DMF, $\mathrm{K}_{2} \mathrm{CO}_{3}$, r.t., $10 \mathrm{~h}, 80 \%$.

Scheme 1 Synthesis of acrylic monomers. 
subjected to column chromatography on silica gel using ethyl acetate and hexane $(1 / 7, \mathrm{v} / \mathrm{v})$ as the eluent to yield 13 (liquid, $1.8 \mathrm{~g}, 70 \%)$. IR ( $\mathrm{KBr}): v_{\max }$ 2962, 1735, 1636, 1472, 1366, 1246, 958, $856 \mathrm{~cm}^{-1} ;{ }^{1} \mathrm{H}$ NMR $(300 \mathrm{MHz}$, $\left.\mathrm{CDCl}_{3}\right) \delta: 1.87\left(\mathrm{~s}, 3 \mathrm{H}, \mathrm{CH}_{3}\right), 2.82\left(\mathrm{t}, 2 \mathrm{H}, \mathrm{CH}_{2}\right), 2.87\left(\mathrm{~d}, 2 \mathrm{H}, \mathrm{CH}_{2}\right), 3.14-$ $3.18\left(\mathrm{~m}, 4 \mathrm{H}, \mathrm{CH}_{2}\right), 4.23\left(\mathrm{t}, 2 \mathrm{H}, \mathrm{CH}_{2}\right), 4.59(\mathrm{t}, 1 \mathrm{H}, \mathrm{CH}), 5.51(\mathrm{~s}, 1 \mathrm{H}, \mathrm{CH}), 6.04$ $(\mathrm{s}, 1 \mathrm{H}, \mathrm{CH}) .{ }^{13} \mathrm{C}$ NMR $\left(75 \mathrm{MHz}, \mathrm{CDCl}_{3}\right)$ 18.5, 31.2, 38.9, 42.1, 53.9, 64.2, 126.2, 136.2, 167.2. MS: Calcd for $\mathrm{C}_{10} \mathrm{H}_{16} \mathrm{O}_{2} \mathrm{~S}_{3}$ : 264.41. Found: $264.03\left[\mathrm{M}^{+}\right]$.

\section{Preparation of polymers}

Synthesis of copolymers (15-19). A flask was charged with a mixture of a monomer $(1.1 \mathrm{mmol})$, methyl methacrylate $(9.9 \mathrm{mmol})$, and a catalytic amount of azobis(isobutyronitrile) $(0.5 \mathrm{mmol})$ and dissolved with $\gamma$-butyrolacton (20 wt $\%)$. The reaction mixture was deoxygenated by an $\mathrm{N}_{2}$-flow for $10 \mathrm{~min}$ and heated at $80^{\circ} \mathrm{C}$ for $18 \mathrm{~h}$ under nitrogen. The progress of the reaction was monitored by TLC. The resulting mixture was poured into methanol $(30 \mathrm{ml})$ and placed in a deep freeze. The resulting solid product was filtered, dissolved in tetrahydrofuran $(5 \mathrm{ml})$, and then poured into methanol $(30 \mathrm{ml})$. After standing overnight, the resulting solid product was filtered to achieve the corresponding solid products 15-19. Further purification was conducted by reprecipitating twice using a tetrahydrofuran-methanol solvent.

\section{RESULTS AND DISUSSION}

We performed the synthesis of functionalized acrylic polymers and optical characterization of polymer films including refractive indices, dispersion and optical transparency. The aim of this research was to obtain synthetic resins with both a high refractive index and good processing performance. The refractive index of an optical material can be increased by incorporating substituent groups, such as amino and nitro groups, or sulfur atoms into acrylate polymers.

We attempted to enhance the refractive index of an acrylic polymer by introducing a polarizing group and sulfur group into the monomer structure. In a previous study, the dipolar acrylate with aminodonating and cyano-withdrawing groups increased the refractive index of acyclic polymer films..$^{5}$ The cyano group can be placed with a nitro group of better polarizing power. Scheme 1 outlines the synthesis of dipolar acrylic monomer 3. It was synthesized by aminoalkylation of 1-fluoro-4-nitrobenzene 1, followed by acrylation with methacrylic anhydride in the presence of a catalytic amount of DMAP, as shown in Scheme 1. We designed several sulfur-containing acrylates to elucidate the high atomic refraction of sulfur. Thus, we prepared one, two and three sulfur atoms attached to acrylic monomers to compare the index change due to sulfur content. Monomer 6 was synthesized by reduction of aldehyde 4 , followed by methacrylation. Monomer 9 was synthesized by dithiolane formation and methacrylation of aldehyde 7. For high sulfur content, alicyclic monomer 13 was also prepared through successive thioalkylation, dithiolane formation and methacrylation. Monomer 14 was designed to investigate the stannyl contribution to refractive index change. The synthesis of $\mathbf{1 4}$ was performed through the recently reported method involving chemoselective acylation with 2 -mercapto ethanol. ${ }^{24}$ The triphenylstannyl group was bound to protect the thiol group, which could inhibit radical polymerization.

Radical polymerization of the prepared functional acrylates generated corresponding linear polymers. Homopolymers provided insufficient solubility to form an optically qualified thin film by a solution process. Thus, all monomers were copolymerized with methyl methacrylate. Polymerization was carried out thermally using azobis(isobutyronitrile) as a radical initiator, as shown in Schemes 2 and 3. Each monomer was mixed with methyl methacrylate in $1: 9,3: 7$ and $5: 5 \mathrm{~mol} \%$ ratios. The NMR study of the resulting polymers presented similar molar compositions to the feeding monomer ratios. Table 1 summarizes the results of gel permission chromatography of the polymers.

The thermal properties of polymers were evaluated with thermogravimetry and differential scanning calorimetry. Most of the $50 \%$ copolymers exhibited good thermal stability with a relatively high degradation temperature ( $5 \%$ weight loss) of around $280^{\circ} \mathrm{C}$ under nitrogen. Glass transitions of the copolymers were observed at higher

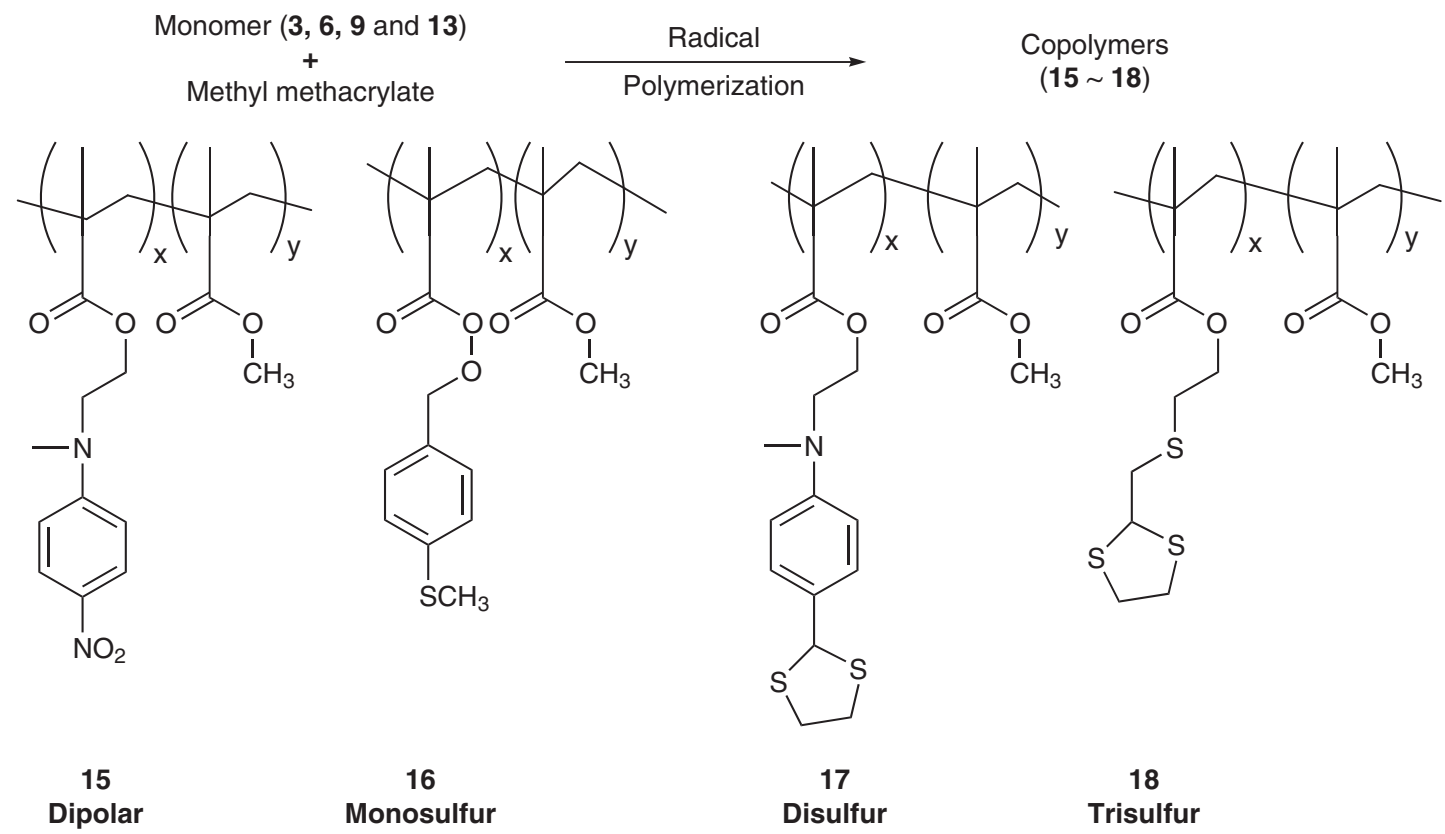

Reagents and polymerization condition:

AIBN, $\gamma$-butyrolacton, methyl methacrylate, heating at $80^{\circ} \mathrm{C}$ for $18 \mathrm{~h}$.

Scheme 2 Copolymer preparation. 


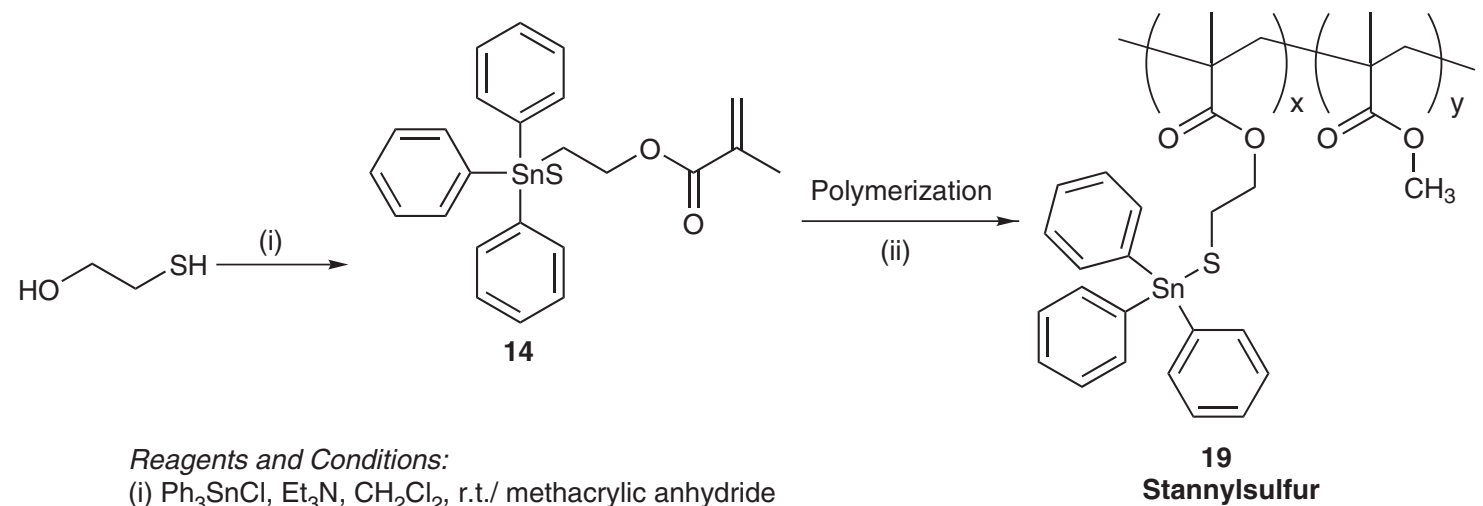

(i) $\mathrm{Ph}_{3} \mathrm{SnCl}, \mathrm{Et}_{3} \mathrm{~N}, \mathrm{CH}_{2} \mathrm{Cl}_{2}$, r.t./ methacrylic anhydride

(ii) AIBN, $\gamma$-butyrolacton, methyl methacrylate, heating at $80^{\circ} \mathrm{C}$ for $18 \mathrm{~h}$.

Stannylsulfur

Scheme 3 Copolymer of a triphenylstannylmercapto-attached acrylate.

Table 1 Gel-permission chromatography analysis of the copolymers ${ }^{a}$

\begin{tabular}{lccc}
\hline & \multicolumn{3}{c}{ Monomer molar ratios } \\
\cline { 2 - 4 } Copolymer & $1: 9$ & $3: 7$ & $5: 5$ \\
\hline Dipolar & $4.2 \mathrm{E} 4(1.9)^{\mathrm{b}}$ & $4.1 \mathrm{E} 4(1.9)$ & $4.9 \mathrm{E} 4(1.6)$ \\
Monosulfur & $3.4 \mathrm{E} 4(2.8)$ & $3.9 \mathrm{E} 4(3.1)$ & $4.4 \mathrm{E} 4(2.5)$ \\
Stannylsulfur & $4.1 \mathrm{E} 4(2.1)$ & $5.2 \mathrm{E} 4(1.9)$ & $6.5 \mathrm{E} 4(1.8)$ \\
Disulfur & $5.1 \mathrm{E} 4(1.9)$ & $4.9 \mathrm{E} 4(2.2)$ & $5.8 \mathrm{E} 4(2.0)$ \\
Trisulfur & $4.3 \mathrm{E} 4(2.1)$ & $4.4 \mathrm{E} 4(2.2)$ & $4.3 \mathrm{E} 4(2.1)$ \\
\hline
\end{tabular}

The data were calibrated with a polystyrene standard and the value indicated weight average molecular weight.

${ }^{\mathrm{b}}$ The parenthesis contains polydispersity index.

Table 2 Thermal and optical analysis of the copolymer films ( 50 mole \%)

\begin{tabular}{lcccc}
\hline Copolymer & TGA $\left({ }^{\circ} \mathrm{C}\right) 5 \%$ loss & DSC $\left({ }^{\circ} \mathrm{C}\right)$ & $\lambda_{\max }(\mathrm{nm})$ & $\lambda_{\text {cut-off }}(\mathrm{nm})$ \\
\hline Dipolar & 277 & 121 & 386 & 460 \\
Monosulfur & 278 & 103 & 263 & 320 \\
Stannylsulfur & 255 & 116 & 280 & 340 \\
Disulfur & 274 & 118 & 274,345 & 385 \\
Trisulfur & 278 & 105 & 275 & 389 \\
\hline
\end{tabular}

than $100^{\circ} \mathrm{C}$. Aliphatic acrylic copolymers (monosulfur and trisulfur) were determined to have a lower glass temperature than aromatic acrylic copolymers (dipolar and disulfur), as shown in Table 2.

Ultraviolet-visible absorption spectra were measured for the polymer films formed on a quartz cell. The films were prepared by spin casting with chloroform solutions. All films exhibited good transparency in the visible region, as shown in Figure 1. Dipolar polymers presented an orange-colored film and exhibited a charge transfer absorption band from $350-450 \mathrm{~nm}$ with a tail up to $467 \mathrm{~nm}$. However, other polymers showed negligible absorption beyond $390 \mathrm{~nm}$, as shown in Table 2. Sulfur-containing polymers were very transparent and we concluded that they were more suitable for various lens applications than were dipolar polymers. The refractive indices of all polymer films were observed at 486, 546, 589 and $656 \mathrm{~nm}$ and are summarized in Table 3 . The results of homopolymers were estimated through extrapolation of copolymer data. The comonomer contribution to the refractive index was linearly proportional to the composi-
Table 3 Measured refractive indices of the polymer films

\begin{tabular}{|c|c|c|c|c|c|}
\hline \multirow[b]{2}{*}{ Copolymer } & \multicolumn{4}{|c|}{ Measurement wavelength ( $\mathrm{nm}$ ) } & \multirow[b]{2}{*}{ Abbe's number ${ }^{2}$} \\
\hline & 486 & 546 & 589 & 656 & \\
\hline \multicolumn{6}{|l|}{ Dipolar } \\
\hline $1: 9$ & 1.560 & 1.555 & 1.549 & 1.546 & \\
\hline $3: 9$ & 1.602 & 1.597 & 1.591 & 1.587 & \\
\hline $5: 5$ & 1.628 & 1.624 & 1.617 & 1.613 & \\
\hline Homopolymer ${ }^{b}$ & 1.668 & 1.663 & 1.654 & 1.652 & 40.9 \\
\hline \multicolumn{6}{|l|}{ Monosulfur } \\
\hline $1: 9$ & 1.560 & 1.551 & 1.545 & 1.540 & \\
\hline $3: 9$ & 1.587 & 1.579 & 1.573 & 1.567 & \\
\hline $5: 5$ & 1.605 & 1.595 & 1.590 & 1.584 & \\
\hline Homopolymer & 1.634 & 1.628 & 1.624 & 1.612 & 29.7 \\
\hline \multicolumn{6}{|l|}{ Stannylsulfur } \\
\hline $1: 9$ & 1.590 & 1.580 & 1.575 & 1.570 & \\
\hline $3: 9$ & 1.628 & 1.616 & 1.611 & 1.607 & \\
\hline $5: 5$ & 1.650 & 1.640 & 1.635 & 1.630 & \\
\hline Homopolymer & 1.682 & 1.672 & 1.668 & 1.660 & 30.4 \\
\hline \multicolumn{6}{|l|}{ Disulfur } \\
\hline $1: 9$ & 1.578 & 1.570 & 1.560 & 1.555 & \\
\hline $3: 9$ & 1.631 & 1.625 & 1.614 & 1.603 & \\
\hline $5: 5$ & 1.660 & 1.650 & 1.639 & 1.635 & \\
\hline Homopolymer & 1.702 & 1.692 & 1.683 & 1.675 & 25.4 \\
\hline \multicolumn{6}{|l|}{ Trisulfur } \\
\hline $1: 9$ & 1.595 & 1.586 & 1.581 & 1.575 & \\
\hline $3: 9$ & 1.654 & 1.645 & 1.639 & 1.634 & \\
\hline $5: 5$ & 1.691 & 1.682 & 1.674 & 1.666 & \\
\hline Homopolymer & 1.745 & 1.731 & 1.725 & 1.718 & 29.0 \\
\hline
\end{tabular}

aAbbe's number $\left(V_{D}\right)$ was calculated using indices at $589.3,486.1$ and $656.3 \mathrm{~nm}$. bThe index of homopolymer was determined from extrapolation of copolymer indices.

tion ratio. Three copolymers with different molar ratios were prepared by control of the monomer-feeding ratio during polymerization. The refractive index increased with the functional comonomer content, and typical wavelength dependency was observed for all polymers. All polymers presented significantly higher refractive indices with high 

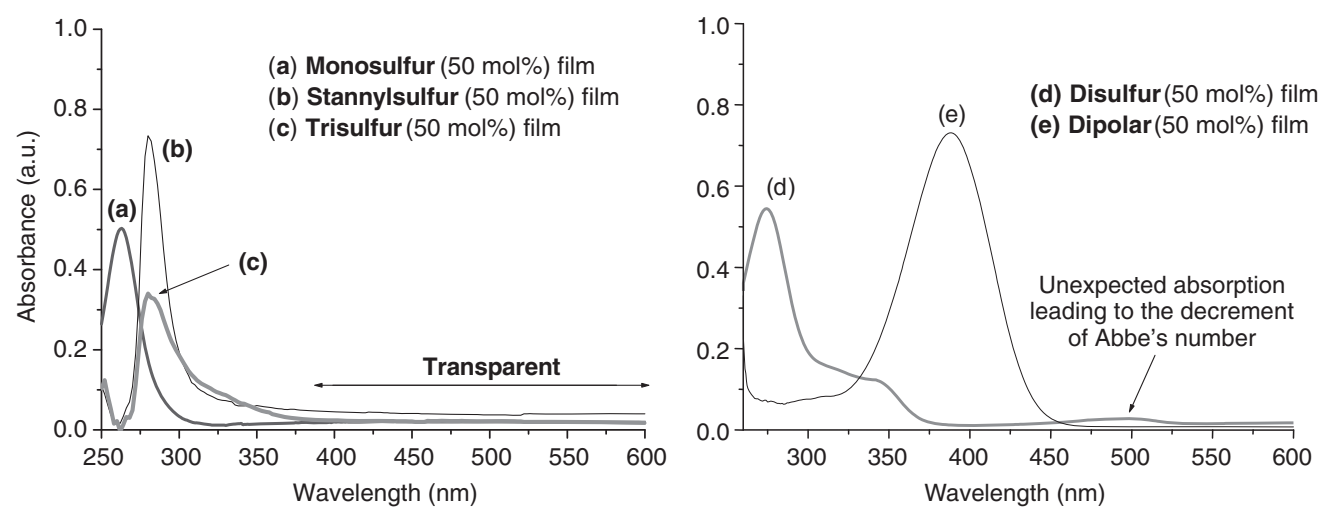

Figure 1 Ultraviolet-visible spectra of copolymer films.

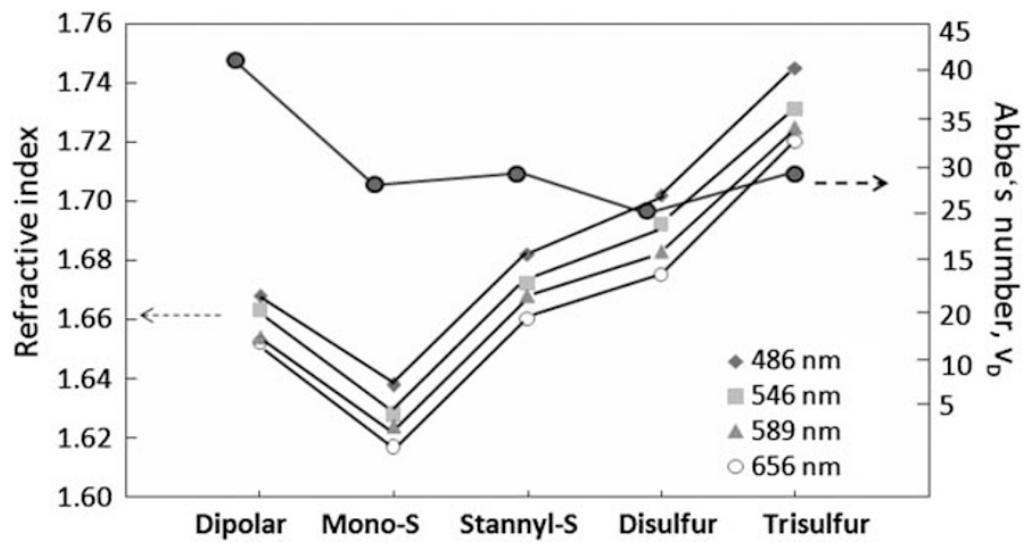

Figure 2 The variation of refractive index and Abbe's number of homopolymer films.

Abbe's numbers compared with those of conventional optical polymers. ${ }^{25}$ The refractive indices of synthesized polymers roughly depend on the number of sulfur atoms in the monomer structure. Figure 2 shows the index increment due to the constituted sulfur number. The fundamental absorptions of optical polymers have to be blue shifted to achieve a low dispersion of refractive indices or a large Abbe's number. This is because the refractive index of condensed matter significantly increases near the absorption edges. ${ }^{26}$ Polymers with a high sulfur content generally have decreased Abbe's numbers. ${ }^{27}$ It is surprising that the orange-colored film of dipolar polymers provided a high Abbe's number of 40.9 when most polymers had an Abbe's number of around 30. The ultraviolet-visible absorption spectrum of disulfur shows the appearance of limited absorption around $500 \mathrm{~nm}$. This resulted in a low Abbe's number of 25.4. The unexpected absorption is attributed to polymer purity caused by monomer purity. A similar absorption pattern was observed with a monomer 9 and was not enhanced with further purification. The sulfur atom and dipolar aromatic ring contributed to the increase in refractive index as expected. Trisulfur afforded the highest index among the prepared polymers and was more than 1.72 in visible light. The index of triphenyl stannyl-attached polymers was a little higher than that of monosulfur. The stannyl contribution to the index increase was not high.

\section{CONCLUSION}

Novel sulfur-containing acrylic monomers were developed for low dispersion and high refractive index and convenient synthesis and characterizations were performed. Trisulfur polymer films provided the highest refractive index among the prepared polymers. The dipolar phenyl structure significantly increased the refractive index of acrylic polymers.

The refractive index of homopolymers was estimated from the several prepared copolymers. The homopolymer of trisulfur was calculated to result in an index of more than 1.72 for visible light. The index of polymer films increased with the number of sulfur atoms in the monomer structure. The wavelength dependency of the refractive index was investigated with Abbe's number for all polymer films. Most sulfur-containing polymers afforded an Abbe's number of $\sim 30$. Exceptionally low wavelength dispersion, providing an Abbe's number of 40.9, was found with a dipolar polymer film.

\section{ACKNOWLEDGEMENTS}

This work was supported by the IT R\&D program (2006-S-073-02) of MKE/ IITA, Korea, and by a grant from the Fundamental R\&D Program for Core Technology of Materials funded by the Ministry of Knowledge Economy, Republic of Korea.

1 Gao, C., Yang, B. \& Shen, J. Study on syntheses and properties of 2,2'-mercaptoethylsulfide dimethacrylate transparent homo- and copolymer resins having high refractive index. J. Appl. Polym. Sci. 75, 1474-1479 (2000).

2 Matsuda, T., Funae, Y., Yoshida, M., Yamamoto, T. \& Takaya, T. Optical material of high refractive index resin composed of sulfur-containing aliphatic and alicyclic methacrylates. J. Appl. Polym. Sci. 76, 45-49 (2000). 
3 Caseri, W. Nanocomposites of polymers and metals or semiconductors: historical background and optical properties. Macromol. Rapid Commun. 21, 705-722 (2000).

4 David, E. C. \& Elliott, B. S. Preparation of a homogeneously dispersed $\mathrm{BaTiO}_{3} /$ polymer nanocomposite thin film. Chem. Mater. 11, 2319-2321 (1999).

5 Kwon, J. Y., Kim, B. G., Do, J. Y., Ju, J. J. \& Park, S. K. Polarizing group attached acrylates and polymers viewing high refractive index. Macromol. Res. 15, 533-540 (2007).

6 Walheim, S., Schaffer, E., Mlynek, J. \& Steiner, U. Nanophase-separated polymer films as high-performance antireflection coatings. Science 283, 520-522 (1999).

7 Dannberg, P., Erdmann, L., Krehl, A., Wächter, C. \& Bräuer, A. Integration of optical interconnects and optoelectronic elements on wafer-scale. Materials Science in Semiconductor Processing 3, 437-441 (2000).

8 Eldada, L. Advances in telecom and datacom optical components. Opt. Eng. 40, 1165-1178 (2001).

9 Ma, H., Jen, A. K. Y. \& Dalton, L. R. Polymer-based optical waveguides: materials, processing, and devices. Adv. Mater. 14, 1339-1365 (2002)

10 Blythe, A. R. \& Vinson, R.J. Polymeric materials for devices in optical fibre systems. Polym. Adv. Technol. 11, 601-611 (2000).

11 Zhou, M. Low-loss polymeric materials for passive waveguide components in fiber optical telecommunication. Opt. Eng. 41, 1631-1643 (2002).

12 Seferis, J. C. Refractive Indices of Polymers in Polymer Handbook, 4th edn. (eds. Brandrup, J., Immergut, E. H. \& Grulke, E. A.) vol. 1, 571 (Wiley, New York, 1999).

13 Ghim, J., Lee, D. S., Shin, B. G., Vak, D., Yi, D. K. \& Kim, M. J. Optical properties of perfluorocyclobutane aryl ether polymers for polymer photonic devices. Macromolecules 37, 5724-5731 (2004).

14 Ding, J., Qi, Y., Day, M., Jiang, J. \& Callender, C. L. A low temperature polycondensation for the preparation of highly fluorinated poly (arylene ether sulfone)s containing crosslinkable pentafluorostyrene moieties. Macromol. Chem. Phys. 206, 2396-2407 (2005).

15 Yi, L., Xiaodonga, W. \& Fan, Y. Microfluidic chip made of COP (cyclo-olefin polymer) and comparion to PMMA (polymethylmethacrylate)microfluidic chip. J. Mater. Proc. Techn. 208, 63-69 (2008).
16 Morishiri, H. \& Kobayashi, S. Jpn. Kokai Tokkyo Koho JP2006131724 (2006). Chem. Abstr. 144, 489903h (2006).

17 Okada, R., Ohkubo, T. \& Kosaka, M. Eur.Pat.Appl., EP 530757 (1993). Chem. Abstr. 119, 97514 (1993).

18 Suzuki, Y., Higashihara, T., Ando, S. \& Ueda, M. Synthesis of high refractive index poly(thioether sulfone)s with high Abbe's number derived from 2,5-Bis(sulfanylmethyl)I,4-dithiane. Polymer J. 41, 860-865 (2009).

19 Okubo, T., Kohmoto, S. \& Yamamoto, M. Optical polymer having a high refractive index and high Abbe number prepared by radical polymerization using 2,5-Bis(2-thia3-butenyl)-1,4-dithiane. J. Macromol. Sci. Pure Appl. Chem. A35, 1819-1834 (1998).

20 Dislich, H. Plastics as optical materials. Angew. Chem. Int. Ed. Engl. 18, 49-59 (1979).

21 Yang, C. J. \& Jenekhe, A. S. Group contribution to molar refraction and refractive index of conjugated polymers. Chem. Mater. 7, 1276-1285 (1995).

22 Okutsu, R., Ando, S. \& Ueda, M. Sulfur-containing poly(meth)acrylates with high refractive indices and high Abbe's numbers. Chem. Mater. 20, 4017-4023 (2008).

23 Okutsu, R., Suzuki, Y., Ando, S. \& Ueda, M. Poly(thioether sulfone)with high refractive index and high Abbe's number. Macromolecules 41, 6165-6168 (2008).

24 Maheswara, M., Kim, M., Yun, S. J., Ju, J. J. \& Do, J. Y. A new strategy for chemoselective $\mathrm{O}$-acylation of $\beta$-mercapto alcohols via alkylsilyl and stannyl protection. Tetrahedron Lett. 50, 480-483 (2009).

25 Cui, Z., Lu, C., Yang, B., Shen, J., Su, X. \& Yang, H. The research on syntheses and properties of novel epoxy/polymercaptan curing optical resins with high refractive indices. Polymer 42, 10095-10100 (2001).

26 Uozu, Y., Hirota, N. \& Horie, K. Improvement of chromatic aberration of the plastic rod-lens array. Macromol. Mater. Eng. 289, 56-62 (2004).

27 Matsuda, T., Funae, Y., Yoshida, M. \& Yamamoto, T. High index optical materials prepared by copolymerization of novel bifunctional thiomethacrylates. Pure. Appl. Chem. A37, 239-257 (2000). 